\title{
Long creep-recovery behavior of bamboo-based products
}

\author{
Xinxin Ma ${ }^{1} \cdot$ Sheldon Q. Shi ${ }^{2} \cdot$ Ge Wang $^{1} \cdot$ Benhua Fei $^{1} \cdot$ Zehui Jiang $^{1}$ \\ Received: 15 April 2017 / Accepted: 28 October 2017 / Published online: 26 December 2017 \\ (C) The Japan Wood Research Society 2017
}

\begin{abstract}
This paper describes the bending creep behavior of two types of bamboo-based products, bamboo-laminated veneer lumber (BLVL), and glued-laminated bamboo (GLB, also called Bamboo Glulam) at different stress levels for half a year and recovery for the same time. It was found that the stress level of BLVL was more sensitive on creep property than that of GLB; the creep resistance of GLB was worse than that of BLVL in the stress levels of 30-50\%; the instantaneous recovery ratio (elastic recovery to elastic creep) decreased with an increase of the stress levels, while the residual ratio (residual deformation corresponded to the total creep deflections) increased with an increase of stress levels for all specimens; Burgers model fit creep data very well for both bamboo-based products, while the recovery Weibull equation does not fit recovery data well for GLB.
\end{abstract}

Keywords Creep $\cdot$ Recovery $\cdot$ Bamboo

\section{Introduction}

Creep-recovery is a deformation response for a typical viscoelastic materials. For the structural design, it is important to understand recovery behavior for the materials, by applying a constant stress for a period of time (i.e., creep) followed by removing the stress, and examining the subsequent relaxation response of the material (i.e., recovery) over a specific duration.

Wood and bamboo are both polymeric material, presenting a time-dependent behavior. Many engineered products have been used as a structural material for buildings, such as laminated veneer lumber (LVL) and glued-laminated timber. Therefore, many research activities have been focused on the creep property of these well-developed engineered products. Studies on creep behavior of wood have been conducted for decades [1]. It was concluded that the level of applied

Benhua Fei

feibenhua@icbr.ac.cn

Zehui Jiang

jiangzehui@icbr.ac.cn

1 Key Laboratory of Bamboo and Rattan Science and Technology of the State Forestry Administration, Department of Biomaterials, International center for Bamboo and Rattan, No. 8, Futong Dong Dajie, Wangjing Area, Chaoyang District, Beijing, China

2 Department of Mechanical and Energy Engineering, University of North Texas, Denton, TX, USA loads, time of load duration, moisture content (MC), and temperature is critical factors affect creep behavior. Based on these previous results, Toratti [2] tested the time-dependent properties of spruce members and established creep model for LVL. The long-term behavior of pre-stressed LVL was tested for 1 year in controlled and uncontrolled indoor conditions. The results indicated that creep and mechano-sorptive creep were far more significant perpendicular to than that of products parallel to grain [3, 4]. Glulam was another well-developed timber mainly used in building structures. Cyclic and viscoelastic creep behaviors of glulam beams were investigated in the numerical modelling [5].

However, limited research has been conducted on the creep property of bamboo-based products. Bamboo has rapid growth rate and good physical property. Research and development of engineered bamboo products is increasingly explored to design sustaniable building materials for the built environment. In China, the market size for bamboo products increased to 122.4 billion RMB or 19.7 billion US dollars in 2012 according to State Forestry Administration of China (2012) [6], which made the bamboo industry a forestry highlight in China. While the use of bamboo is hampered by the lack of engineering data for creep and recovery properties. Some researchers studied the creep property of bamboo and obtained some effect factors. Kanzawa et al. [7] showed that density of bamboo was an important factor affecting the initial deflection more than the long-term creep and indicated the effect of fiber volume and the susceptibility 
of the lignin to creep. The creep behavior of bamboo at constant MC [8] and variable MC [9] were studied, respectively. The results indicated that the creep and mechano-sorptive creep were both related to the ratio of the vascular bundle to parenchyma. On this basis, three years' creep of laminated bamboo truck load bridge was tested, indicating that the bamboo girders have sufficient capacity to meet durability needs of practical use [10]. In addition, short-term creep of bamboo-based particle panel, plybamboo form [11], and some other bamboo-based composites were also investigated. However, little information is available on the longterm creep behavior for the engineered bamboo products.

Two examples of engineered bamboo, similar structure with wood-based products, bamboo-laminated veneer lumber (BLVL) and glued-laminated bamboo (GLB) has been gradually used in buildings and bridges in China. The present work investigates the long-term creep-recovery properties of BLVL and GLB. The structure and element shape of these two products were very representative in bamboo products. The creep research on the two products was important in engineering bamboo field. Therefore, the bending creep-recovery tests under different loadings were performed in this study. An empirical creep-recovery models were developed.

\section{Experimental}

\section{Materials}

Three-year-old bamboo (Neosinocalamus affinis) grown in Sichuan Province, China was obtained. BLVL was prepared by an intermittent hot-pressing process following the process described in Deng [12] and Chen [13]: first, an untwining machine was used to broom and roll the bamboo strips into laminated sheets; then, the sheets were immersed into the adhesive solution (phenol formaldehyde adhesive) for $7 \mathrm{~min}$ and dried to $10 \pm 2 \% \mathrm{MC}$; the assemble bundles were prepressed with a temperature of $60{ }^{\circ} \mathrm{C}$ and a prepress pressure of $1.5 \mathrm{MPa}$ for $15 \mathrm{~min}$. Finally, the compact bamboo bundle veneers were hot-pressed at a temperature of $150{ }^{\circ} \mathrm{C}$ and pressure of $3 \mathrm{MPa}$. Figure 1 shows the schematic diagram of the intermittent hot-press technology. The size of boards was $600 \mathrm{~mm} \times 300 \mathrm{~mm} \times 20 \mathrm{~mm}$.

GLB was manufactured from moso bamboo (Phyllostachys pubescens), grown in Anhui Province, China. They were made by the strands of bamboo glued together to form rectangular cross sections with similar shape and size to the conventional lumber. There were four steps to accomplished. First, bamboo sections were ripped through the length to form strands. Second, the strands were removed the bamboo rind and tabasheer. Then edge glued into small rectangular sections called slats. Finally, the slats were laminated

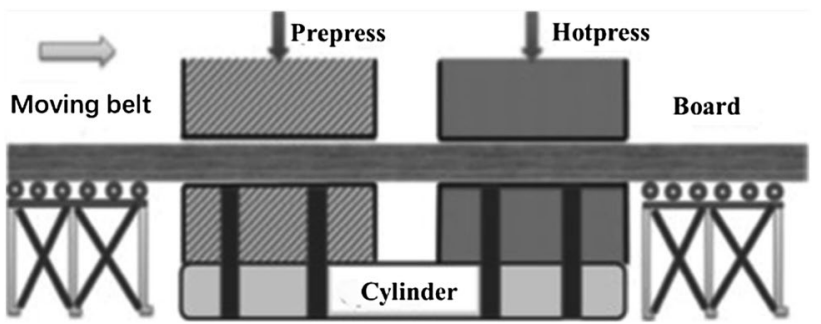

Fig. 1 Schematic diagram of the intermittent hot-pressing process [13]

horizontally with an adhesive to form a row. The size was the same as BLVL.

Then, the specimens were cut from the boards. The size of specimens was $500 \mathrm{~mm} \times 20 \mathrm{~mm} \times 20 \mathrm{~mm}$, which can be seen in Fig. 2. Prior to the creep test, four-point bending tests were conducted according to Chinese national standard GB/T 17,657-2013 [14]. The loading direction was parallel to glue plane. For each panel, six specimens were tested in bending. The loading details can be seen in Fig. 3. The density of bamboo panels, as well as their bending modulus of rupture (MOR), and modulus of elasticity (MOE) were calculated from the bending test data. The average mechanical properties of the test are given in Table 1. The maximum load was used to determine the applied stress level.

\section{Creep and recovery measurements}

The test procedure described in ASTM D 6815 [15] was followed. Creep and recovery behavior of BLVL and GLB were studied by a four-point bending tests using a device, as shown in Fig. 4. The size of all the specimens was $500 \mathrm{~mm} \times 20 \mathrm{~mm} \times 20 \mathrm{~mm}$. The span length was $360 \mathrm{~mm}$ and the load span length was $120 \mathrm{~mm}$. The loading details were similar as that of bending test. Three different series of load levels were applied, which was 30,50 , and $70 \%$ of maximum load. Two specimens were tested for each stress level. The deflection was measured by a dial gauge with an accuracy of $0.01 \mathrm{~mm}$, which was installed at the center of specimens. Bending creep tests were carried out for 6 months (June 2014-November 2014) and then recovered for another 6 months. The creep data were recorded every $3 \mathrm{~min}$ in the first hour, every $30 \mathrm{~min}$ in next $3 \mathrm{~h}$, every day in the first month, and then once a week for the rest of the testing period. The recovery was recorded at the same time schedule with creep test. The experiment was carried on a basement, which the environment was not controlled.

The temperature and relative humidity as a function of time are shown in Fig. 5. During the first 5 months, the average values of temperature and relative humidity were $24{ }^{\circ} \mathrm{C}$ and 50\%, respectively. During the creep testing, the 
Fig. 2 Specimens of BLVL (a) and GLB (b) (a)

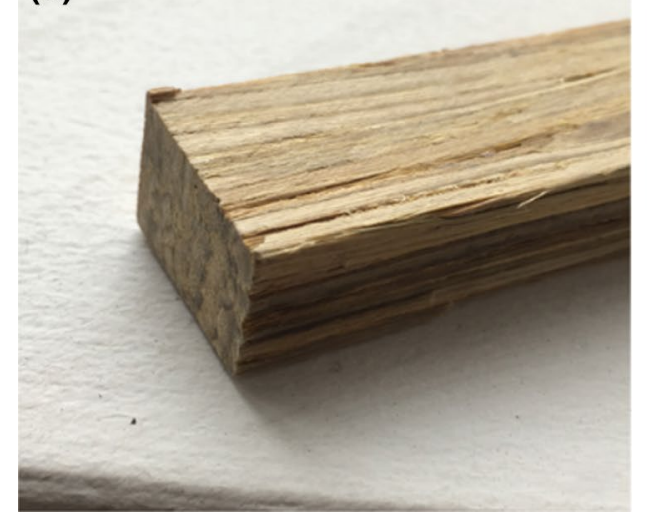

(b)

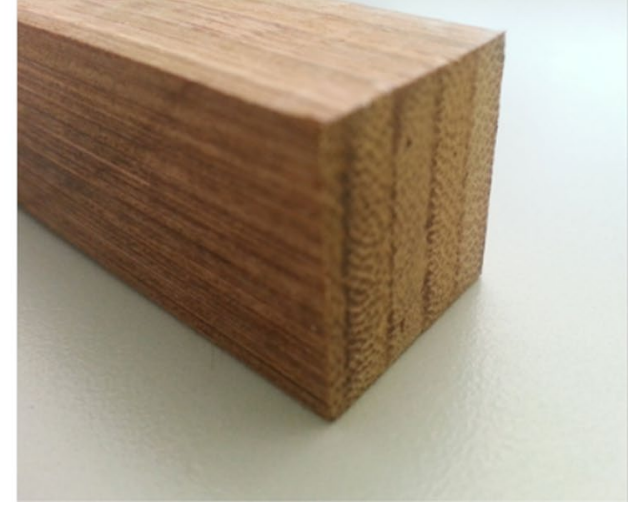

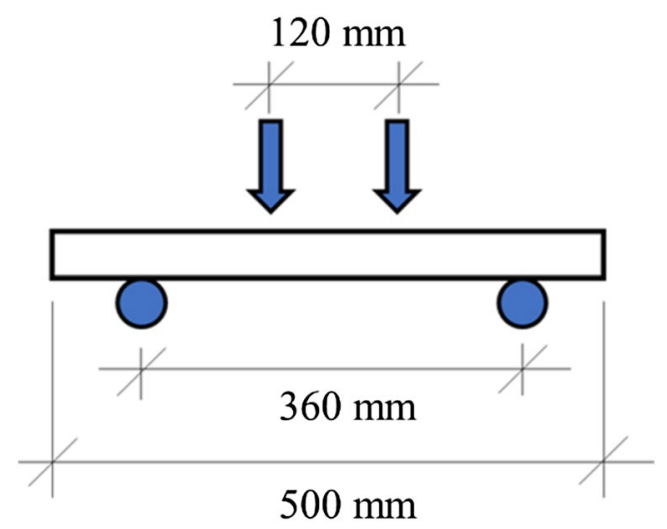

Fig. 3 Loading details of bending test

temperature was between 16 and $20{ }^{\circ} \mathrm{C}$, while the relative humidity was between $22-40 \%$.

\section{Results and discussion}

\section{Effects of stress levels on creep-recovery property of two panels}

The creep-recovery curves of BLVL and GLB in different stress levels are presented in Fig. 6. BLVL and GLB had similar creep-recovery curves. For all the specimens, the elastic deformation was the instantaneous deformation at the loading. When the load was removed, the elastic deformation was recovered instantaneously. The deformation continued to recover over time, of which in this period of time is called delayed-elastic deformation. At the end of creep experiment, the recovery has not been fully recovered. This deformation which not recovered called residual deformation. With time increasing, the recovery seemed to be continued until the recovery complete. This permanent and non-recoverable deformation is a viscous deformation. The observed creep-recovery process for both BLVL and GLB follows the same pattern of polymeric materials described in Nielsen [16] (Fig. 7).

For the two types of bamboo-based products, the creep deformation increased as the stress level increased. The higher the stress level, the more damage for the product structure, and the more physical properties reduction for the bamboo-based products. The creep-recovery parameters are calculated and are shown in Table 2 . The relative creep was quantified for creep behavior of the bamboobased products. The relative creep was calculated ranging from 0.19 to 0.49 for BLVL, increased by 1.58 times when the stress level increased from 30 to $70 \%$. For the GLB products, the relative creep was ranged from 0.41 to 0.56 , which increased by 0.36 times compared to the BLVL. It is seen that the increase rate for BLVL (1.58 times) was much higher than that of GLB (0.36 times), indicating that stress level was more sensitive on creep property for BLVL than that of GLB. The highest relative creep was shown for the GLB samples, indicating that the creep resistance of GLB was worse than that of BLVL for the stress levels of $30-50 \%$.
Table 1 Mechanical properties of two panels

\begin{tabular}{lllllll}
\hline Material type & Density $\left(\mathrm{g} / \mathrm{cm}^{3}\right)$ & MOR $(\mathrm{MPa})$ & S.D. $(\mathrm{MPa})$ & MOE $(\mathrm{GPa})$ & S.D. $(\mathrm{GPa})$ & Maximum load (N) \\
\hline BLVL & 0.90 & 193.65 & 8.8 & 24.14 & 1.25 & 4505.00 \\
GLB & 0.75 & 93.73 & 11.7 & 9.72 & 2.21 & 2022.00 \\
\hline
\end{tabular}

MOR modulus of rupture, MOE modulus of elasticity, S.D. standard deviation, BLVL bamboo-laminated veneer lumber, $G L B$ glue laminated bamboo 


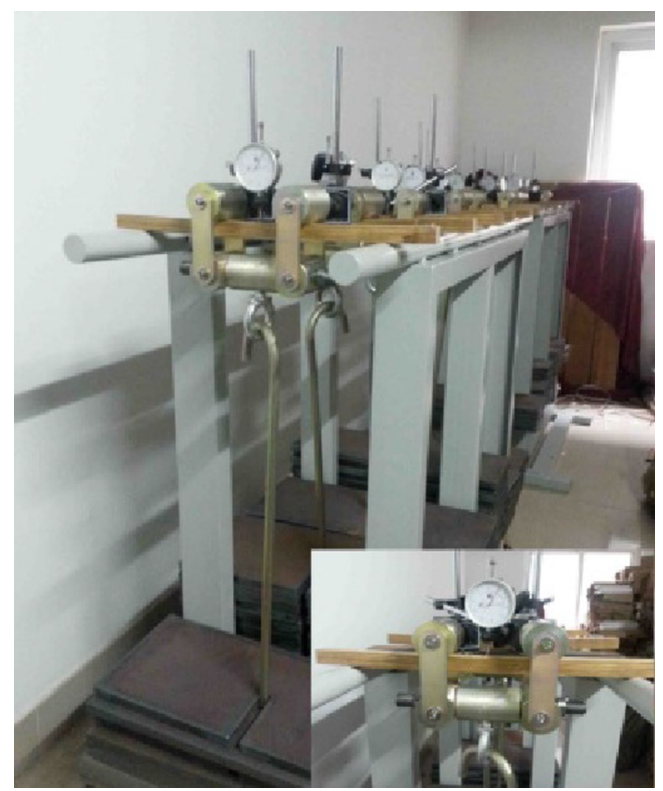

Fig. 4 Creep test setup

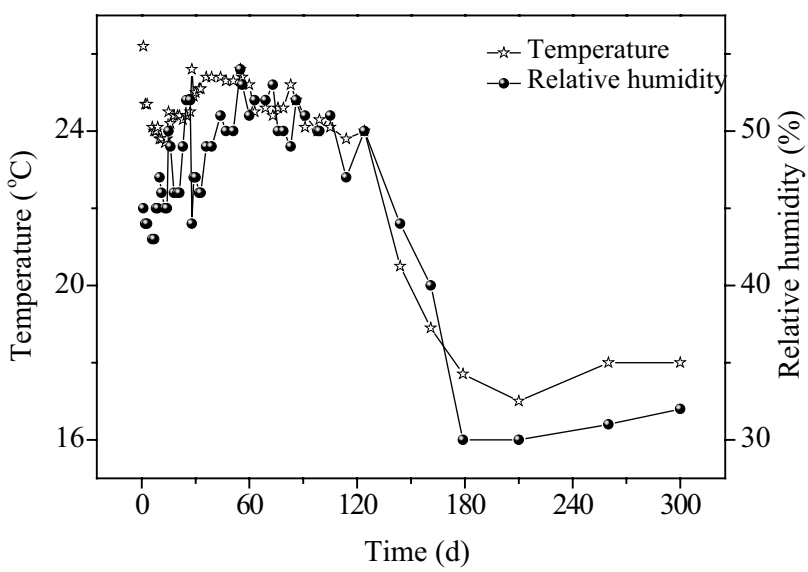

Fig. 5 Temperatures and relative humilities during the creep testing

After the load was removed, the recovery deformation exhibited a substantial decrease in the first week, and then became relatively stable thereafter. The instantaneous recovery ratio (elastic recovery to elastic creep) is to measure the instantaneous recovery response at the time of unloading. The instantaneous recovery ratios were decreased from 85.48 to $71.40 \%$ for BLVL while $95.77-54.36 \%$ for GLB. The results indicated that instantaneous recovery ratio reduced as the stress level increased. The instantaneous recovery ratio for GLB was higher than that of BLVL at the same stress level, indicating that GLB has a better instantaneous recovery ability.

The residual ratios (residual deformation corresponded to the total creep deflections) at different stress levels were

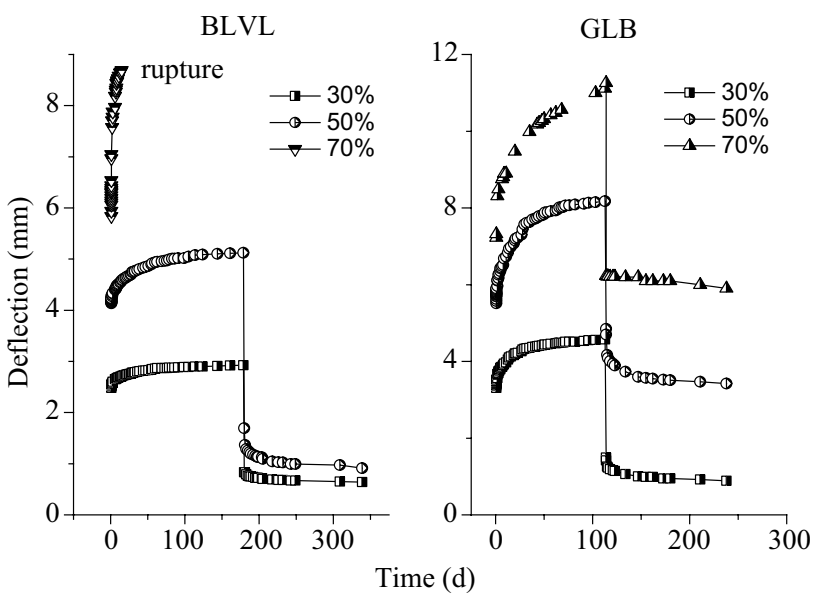

Fig. 6 Creep recoveries of BLVL and GLB, corresponding to different applied stress levels

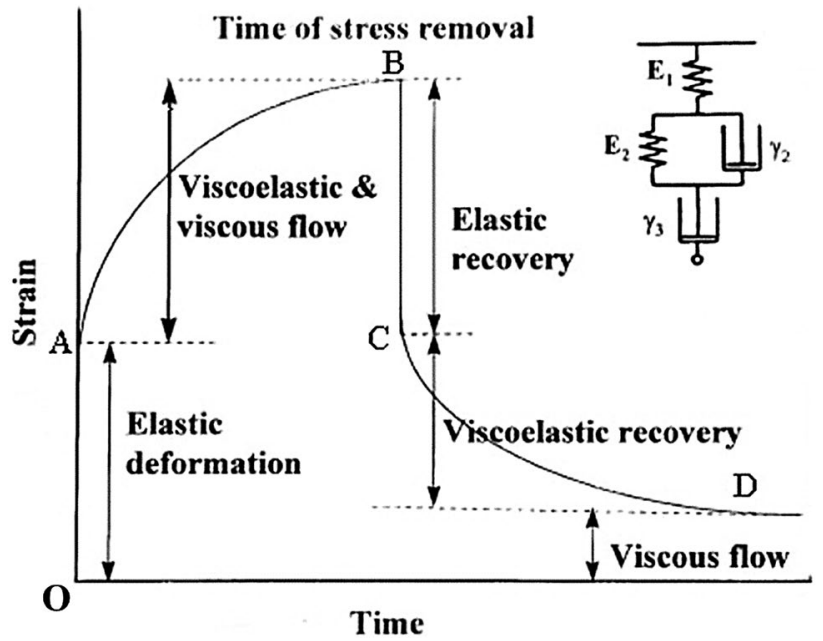

Fig. 7 Typical polymer deformation profile on application of constant stress and recovery on stress removal [16]. The strain in O-A is $E_{\mathrm{c}}$, O-B is $T_{\mathrm{c}}, \mathrm{B}-\mathrm{C}$ is $E_{\mathrm{r}}$, but $\mathrm{O}-\mathrm{D}>R_{\mathrm{d}}$, because the recovery in this experiment is not fully. These are also shown in Table 2.

also calculated. When the stress level was increased from 30 to $50 \%$, the residual ratios were increased from 21.69 to $30.87 \%$ for the BLVL samples and from 19.10 to $61.28 \%$ for the GLB samples when the stress level increased from 30 to $70 \%$. These results indicated that the residual part of creep deformations was increased with rise of stress level.

\section{Creep rate of two materials in variable environment}

The creep deflections were recorded between five equally spaced time segments for the determination of a decreasing creep rate. Six equal time periods were used, 0 to 30 days, 30 to 60 days, 60 to 90 days, 90 to 120 days, 120 to 150 days and 150 to 180 days, denoted as $D_{\mathrm{i}}$ as the initial 
Table 2 Creep-recovery parameters at different loading stresses

\begin{tabular}{|c|c|c|c|c|c|c|c|c|}
\hline \multirow[t]{2}{*}{ Material } & \multirow[t]{2}{*}{ Stress } & \multicolumn{3}{|l|}{ Creep } & \multicolumn{2}{|l|}{ Recovery } & \multirow{2}{*}{$\begin{array}{l}\text { Recovery } \\
\text { ratio }\left(E_{\mathrm{r}} / E_{\mathrm{c}}\right)\end{array}$} & \multirow{2}{*}{$\begin{array}{l}\text { Residual } \\
\text { ratio } \\
\left(R_{\mathrm{d}} / T_{\mathrm{c}}\right)\end{array}$} \\
\hline & & $E_{\mathrm{c}}(\mathrm{mm})$ & $T_{\mathrm{c}}(\mathrm{mm})$ & $R_{\mathrm{c}}$ & $E_{\mathrm{r}}(\mathrm{mm})$ & $R_{\mathrm{d}}(\mathrm{mm})$ & & \\
\hline \multirow[t]{3}{*}{ BLVL } & $30 \%$ & 2.48 & 2.95 & 0.19 & 2.12 & 0.61 & $85.48 \%$ & $21.69 \%$ \\
\hline & $50 \%$ & 4.45 & 5.28 & 0.19 & 3.27 & 1.63 & $71.40 \%$ & $30.87 \%$ \\
\hline & $70 \%$ & 5.84 & 8.69 & 0.49 & - & - & - & - \\
\hline \multirow[t]{3}{*}{ GLB } & $30 \%$ & 3.31 & 4.66 & 0.41 & 3.17 & 0.89 & $95.77 \%$ & $19.10 \%$ \\
\hline & $50 \%$ & 5.51 & 8.30 & 0.51 & 3.95 & 3.18 & $71.62 \%$ & $38.31 \%$ \\
\hline & $70 \%$ & 7.23 & 11.26 & 0.56 & 3.93 & 6.90 & $54.36 \%$ & $61.28 \%$ \\
\hline
\end{tabular}

Some of these parameters are shown in Fig. 6

$E_{c}$ elastic deformation, $T_{c}$ total creep, $R_{c}$ relative creep $\left(\left(T_{\mathrm{c}}-E_{\mathrm{c}}\right) / E_{\mathrm{c}}\right), E_{r}$ elastic recovery, $R_{d}$ residual deformation, $B L V L$ bamboo-laminated veneer lumber, $G L B$ glued-laminated bamboo

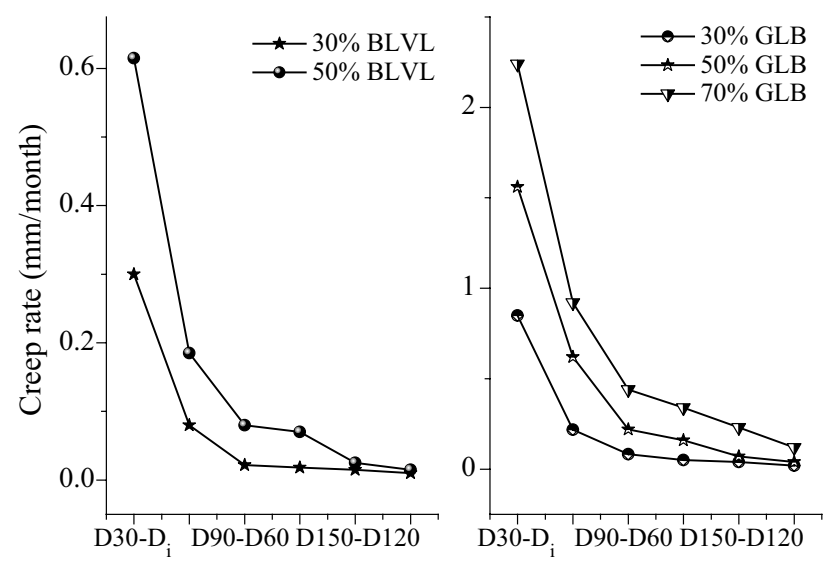

Fig. 8 Creep rate of BLVL and GLB

deflection (measured $1 \mathrm{~min}$ after application of the load), and $D_{30}, D_{60}, \ldots D_{180}$ are those measured on 30 th, $60^{\text {th }}$, and 180 th days, respectively. The decreasing creep rate can be expressed as difference value of creep deflection, as shown in Fig. 8.

As shown in Fig. 8, the creep rate of two specimens was all decreased as a function of creep time, $D_{30}-D_{\mathrm{i}}>D_{60^{-}}$ $D_{30}>D_{90}-D_{60}>D_{120}-D_{90}>D_{150}-D_{120}>D_{180}-D_{150}$. At the stress level of $30 \%$ for BLVL and GLB, the creep rate decreased rapidly during the first three stages (0-90 days). Then, it decreased slowly starting from the fourth stage, tapered off to zero until the last stage. From the stress level of 50 and $70 \%$, the creep rate has similar trend before the third stage. From the fourth stage, the creep rate decreased slower than that in the previous stages. However, it continued to trend down at last stage, not stable as that in the stress level of $30 \%$. The creep rate highly correlates to the applied stress. From our test data, the initial creep rate at stress level of $50 \%$ was two times $(0.615 / 0.3)$ higher than that at a stress level of $30 \%$ for the BLVL samples, while 1.8 times $(1.56 / 0.85)$ higher for the GLB samples.
Table 3 Mechanical properties of intermittent hot-pressing board and non-intermittent hot-pressing board

\begin{tabular}{lll}
\hline Hot-pressing way & MOR (MPa) & MOE (GPa) \\
\hline Intermittent hot-pressing board & 193.65 & 24.14 \\
non-intermittent hot-pressing board & 257.75 & 26.14 \\
\hline
\end{tabular}

$M O R$ modulus of rupture, $M O E$ modulus of elasticity

One BLVL specimen failed at the $70 \%$ stress level (Fig. 6). All the BLVL specimens were prepared by intermittent hot-pressing process. This process is convenient to lengthen bamboo-based engineering material. However, the intermittent hot joints decreased the MOE and MOR of BLVL [13].

The MOE and the MOR of intermittent hot-press technology was different from which non-intermittent (Table 3). The panels made by non-intermittent hot-press technology has no intermittent hot joints and adjacent positions. The specimens made by two different hot-press technology were both tested in perpendicular to the loading direction. MOE and MOR on intermittent hot joints decreased by 7.7 and $24.9 \%$. This result was shown in accordance with that reported [13]. The main reason is a weak point arose in the process of the hot-press joint. In creep study, the failure location was at the intermittent hot-press joint, indicating that the hot-press joint was an important factor of creep property for BLVL.

\section{Creep and recovery modelling}

Various numerical models have been used to predict the creep-recovery behavior. Burgers model is a combination of Maxwell and Kelvin-Voigt models, which commonly used for determining creep behavior:

$\varepsilon_{\mathrm{c}}(t)=\frac{\sigma_{0}}{E_{\mathrm{e}}}+\frac{\sigma_{0}}{E_{\mathrm{de}}}\left[1-\exp \left(\frac{E_{\mathrm{de}}}{\eta_{\mathrm{de}}} t\right)+\frac{\sigma_{0}}{\eta_{v}} t\right]$ 
where $t$ denotes the time, $\sigma_{0}$ the stress, $E_{\mathrm{e}}$ is the elastic modulus of Maxwell spring, which determines the immediate strain $\sigma_{0} / E_{\mathrm{e}}$, and $\eta_{v}$ is the viscosity associated with its dashpot. $E_{\mathrm{de}}$ and $\eta_{\mathrm{de}}$ are the elastic modulus and viscosity of the Kelvin-Voigt spring and dashpot.

In addition, it can also write as

$\varepsilon_{c}(t)=\varepsilon_{1}+\varepsilon_{2}\left[1-\exp \left(-\beta_{3} t\right)\right]+\beta_{4} t$

where $\varepsilon_{1}$ is the initial instantaneous strain, $\varepsilon_{2}$ and $\beta_{3}$ represent the creep component, which is determined by the characteristic life and shape parameters as a function of load duration $t . \beta_{4}$ is the irrecoverable creep component.

When the load is removed, there are some instantaneous strain recovery. It is followed by time-dependent recovery strain. In the recovery curve, it only contained C-D stage (Fig. 7). First, elastic element can be omitted. Second, a single retardation time is not sufficient to describe the relaxation process, because there is a distribution of retardation times [17]. Third, there will be a viscous flow (permanent deformation) when the recovery complete. Therefore, the recovery model can be given by a Weibull distribution equation [18]:

$\boldsymbol{\varepsilon}_{r}(t)=\varepsilon_{3}\left[\exp \left(-\left(\beta_{r} t\right)^{n}\right)\right]+\varepsilon_{4}$

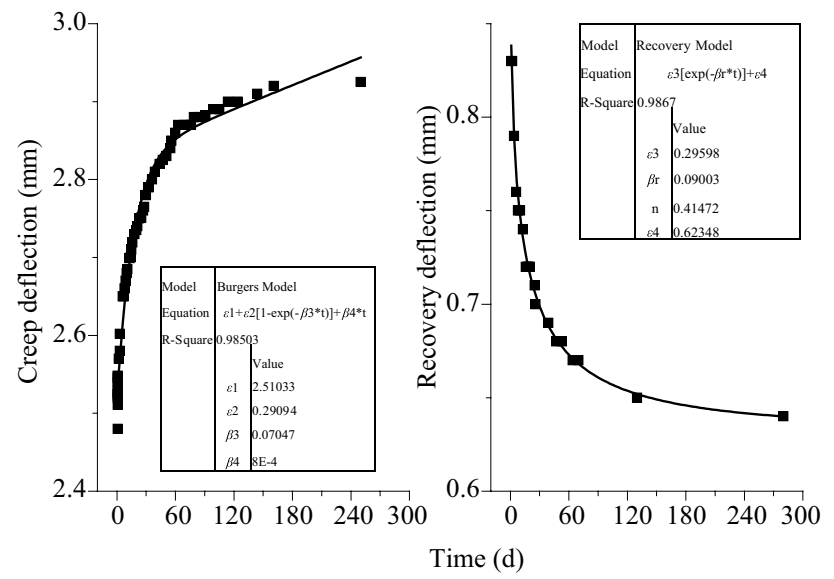

Fig. 9 Typical creep and recovery data of BLVL at 30\% stress level where $\varepsilon_{3}$ is viscoelastic strain recovery, which is determined using the same parameters in Eq. 2 over recovery time $t$, the stretching exponent $n$ is determined by the width of retardation time distribution, and the shape parameter $\beta_{r}$ and $\varepsilon_{4}$ is the permanent strain from viscous flow. Based on Ref. [19], this equation correlated very well with experimental data from semi-crystalline polymers. It enabled both timedependent and time-independent strains to be predicted.

All the creep-recovery coefficients were simulated by the OriginPro software. Figure 9 shows the typical curve of creep and recovery data for BLVL at 30\% stress level. The creep data are fitted to Eq. 2, while recovery data are fitted to Eq. 3. All the coefficients can be obtained by "Nonlinear curve fit" of Origin 8.5. The results are shown in Table 4.

The creep and recovery curves of all specimens fitted with Burgers model very well. Parameters of creep and recovery are determined in Table 2 . The average coefficients of determination for creep curves were obtained as $R^{2}=0.99$ for both BLVL and GLB, and the average coefficients for the recovery curves were obtained as $R^{2}=0.95$ for the BLVL, and $R^{2}=0.94$ for the GLB.

According to Eq. (2), $\varepsilon_{1}$ is the Maxwell spring related to the instantaneous elastic creep strain. GLB showed higher $\varepsilon_{1}$ value than that of BLVL. The retardant elasticity $\varepsilon_{2}$ and shape parameter $\beta_{3}$ were time dependent. They are viscoelastic parts in the creep model. The effect of stress level on the retardant elasticity $\varepsilon_{2}$ showed similar trend to $\varepsilon_{1}$. The data of $\varepsilon_{2}$ increased by the stress level increased. Based on Eqs. (1) and (2), $\varepsilon_{2}$ is equal to $\sigma_{0} / E_{\mathrm{de}}$. When $\varepsilon_{2}$ increased, $E_{\text {de }}$ decreased. It is indicated that the applied stress has an ability to reduce the $E_{\mathrm{de}}$. However, $\beta_{3}$ has no specific relationship with the stress level.

The parameter $\beta_{4}$ in creep model is very sensitive to the stress level. In general, the $\beta_{4} t$ term in the creep model represents the irrecoverable creep, which has the same meaning with $\varepsilon_{4}$ in recovery model. During our creep test, when the stress was applied to the specimens, the strain increased sharply, because the molecular bonds stretch beyond the elastic limit, but not broken, which can be described by the dashpot element of the Maxwell model $\left(\beta_{4}\right)$.
Table 4 Creep and recovery coefficients of Burgers model

\begin{tabular}{|c|c|c|c|c|c|c|c|c|}
\hline \multirow[t]{2}{*}{ Species } & \multirow{2}{*}{$\begin{array}{l}\text { stress } \\
\text { level (\%) }\end{array}$} & \multicolumn{4}{|c|}{ Creep parameter } & \multirow{2}{*}{$\begin{array}{l}\text { Correlation } \\
\text { coefficient } \\
R^{2}\end{array}$} & \multirow{2}{*}{$\begin{array}{l}\text { Recovery } \\
\text { parameter } \\
\varepsilon_{4}\end{array}$} & \multirow{2}{*}{$\begin{array}{l}\text { Correlation } \\
\text { coefficient } \\
R^{2}\end{array}$} \\
\hline & & $\varepsilon_{1}$ & $\varepsilon_{2}$ & $\beta_{3}$ & $\beta_{4}$ & & & \\
\hline \multirow[t]{2}{*}{ BLVL } & 30 & 2.51 & 0.29 & 0.07 & 0.0008 & 0.99 & 0.62 & 0.98 \\
\hline & 50 & 4.17 & 0.64 & 0.06 & 0.0020 & 0.99 & 1.63 & 0.91 \\
\hline \multirow[t]{3}{*}{ GLB } & 30 & 3.36 & 1.07 & 0.06 & 0.0013 & 0.99 & 0.73 & 0.97 \\
\hline & 50 & 5.57 & 2.46 & 0.05 & 0.0014 & 0.99 & 3.37 & 0.95 \\
\hline & 70 & 7.25 & 2.58 & 0.10 & 0.0140 & 0.98 & 6.77 & 0.90 \\
\hline
\end{tabular}

$\varepsilon_{1}$ initial instantaneous strain, $\varepsilon_{2}$ and $\beta_{3}$ creep components determined by characteristic life and shape parameters, $\beta_{4}$ irrecoverable creep component, $B L V L$ bamboo-laminated veneer lumber, $G L B$ glue laminated bamboo 
The recovery parameter $\varepsilon_{4}$ is related to the recovery property, corresponding to residual deformation $\left(R_{\mathrm{d}}\right)$ obtained by the experimental measurements, as shown in Table 2 . The parameter $\varepsilon_{4}$ of BLVL was more close to residual deflection than that of GLB, indicating that the recovery model was better to fit BLVL.

\section{Conclusion}

1. The stress level was more sensitive on creep property for BLVL than GLB. The relative creeps were ranged from 0.19 (30\% stress level) to 0.49 (70\% stress level) for BLVL, increased by $61.2 \%$ and from 0.41 (30\% stress level) to 0.56 (70\% stress level) for GLB, increased by $26.8 \%$.

2. The creep resistance of GLB was less than that of BLVL from stress level of $30-50 \%$. The relative creep of GLB was obtained as $0.41,2.2$ times than that of BLVL at stress level of $30 \%$, while 2.7 times at stress level of $50 \%$.

3. For both BLVL and GLB, the instantaneous recovery ratio (elastic recovery to elastic creep) was reduced with the stress level increased, while residual ratio (residual deformation corresponded to the total creep deflections) was increased.

4. Burgers model fits the creep data very well for both BLVL and GLB with $R^{2}>0.94$. The viscous parameter $\varepsilon_{4}$ of BLVL was more close to the residual deflection obtained from experiment data than that of GLB, indicating that the recovery model fit better for BLVL than that of GLB.

Acknowledgements This work was supported by The International Centre for Bamboo and Rattan, China, and was funded by China's "13th Five-Year Plan" to support science and technology project, Grant No. 2016YFD0600900.

\section{References}

1. Kingston RST, Armstrong LD (1951) Creep in initially green wooden beams. Austr J Appl Sci 2(2):306-325
2. Toratti T (1988) The creep properties of Kerto-laminated-veneerlumber. Research Report. Helsinki University of Technology, Helsinki

3. Davies M, Fragiacomo M (2011) Long-term behavior of prestressed LVL members. I: experimental tests. J Struct Eng 137:1553-1561

4. Fragiacomo M, Davies M (2011) Long-term behavior of prestressed LVL members II: analytical approach. J Struct Eng 137:1562-1572

5. Anshari B, Guan ZW, Kitamori A, Jung K, Komatsu K (2012) Structural behavior of glued laminated timber beams pre-stressed by compressed wood. Constr Build Mater 29:24-32

6. State Forestry Administration of China (2012) Statistical Yearbook of Forestry

7. Kanzawa E, Aoyagi S, Nakano T (2011) Vascular bundle shape in cross-section and relaxation properties of moso bamboo (Phyllostachys pubescens). Mat Sci Eng C 31(5):1050-1054

8. Aoyagi S, Nakano T (2009) Effect of longitudinal and radial position on creep for bamboo (in Japanese). J Soc Mat Sci Jpn 58:57-61

9. Tsubaki T, Nakano T (2010) Creep behavior of bamboo under various desorption conditions. Holzforschung 64:489-493

10. Li L, Xiao Y, Yang R (2012) Experimental study on creep and mechanical behavior of modern bamboo bridge structure. Key Eng Mater 517:141-149

11. Yu YS, Bao Y (2008) Study on creep performance of plybamboo form (in Chinese). For Sci Technol 33(2):47-50

12. Deng JC, Chen FM, Li HD, Wang G, Shi SQ (2014) The effect of PF/PVAC weight ratio and ambient temperature on moisture absorption performance of bamboo-bundle laminated veneer lumber. Polym Composite 37(3):955-962

13. Chen FM, Jiang ZH, Wang G, Li HD, Smith LM, Shi SQ (2016) The bending properties of bamboo bundle laminated veneer lumber (BLVL) double beams. Constr Build Mater 119:145-151

14. GBT 17657-2013 (2013) Test methods of evaluating the properties of wood-based panels and surface decorated wood-based panels (in Chinese). China Standards Press, China

15. ASTM D 6815-09 (2015) Evaluation of duration of load and creep effects of wood and wood-based products. ASTM Committee, United States

16. Nielsen (1974) Mechanical properties of polymers and composites, vol 1. Marcel Dekker, New York

17. Faraz MI, Besseling NAM, Korobko AV, Picken SJ (2015) Characterization and modeling of creep behavior of a thermoset nanocomposite. Polym Composite 36(2):322-329

18. Ounjaijom T, Rangsri W (2016) Numerical and experimental study of the transverse creep-recovery behavior of bamboo culm (Dendrocalamus hamiltonii). Walailak J Sci \&Techno1 3(8):615-629

19. Kevin S, Fancey (2005) A mechanical model for creep, recovery and stress relaxation in polymeric materials. J Mater Sci 40(18):4827-4831 